\title{
Field evaluation of sticky BR-OVT traps to collect culicids eggs and adult mosquitoes inside houses
}

\author{
Morgana do Nascimento Xavier ${ }^{[1],[2], ~ E l o i ́ n a ~ M a r i a ~ d e ~ M e n d o n c ̧ a ~ S a n t o s ~}{ }^{[2]}$, \\ Ana Paula Alves da Silva ${ }^{[3]}$, Plínio Pereira Gomes Júnior ${ }^{[3]}$, \\ Rosângela Maria Rodrigues Barbosa ${ }^{[2]}$ and Cláudia Maria Fontes de Oliveira ${ }^{[2]}$
}

\begin{abstract}
[1]. Programa de Pós-Graduação em Biociências e Biotecnologia em Saúde, Instituto Aggeu Magalhães, Fundação Oswaldo Cruz, Recife, PE, Brasil. [2]. Departamento de Entomologia, Instituto Aggeu Magalhães, Fundação Oswaldo Cruz, Recife, PE, Brasil.

[3]. Unidade Acadêmica de Serra Talhada, Universidade Federal Rural de Pernambuco, Serra Talhada, PE, Brasil.
\end{abstract}

\begin{abstract}
Introduction: Culex quinquefasciatus is a mosquito of importance to public health, as it represents a real and/or potential risk for the transmission of pathogens to humans, such as some arthropod-borne viruses and nematodes that cause filariasis. In Brazil, three municipalities in the Metropolitan Region of Recife (RMR) that are endemic for lymphatic filariasis conducted control actions targeting this vector. With the goal of contributing novel C. quinquefasciatus collection strategies, a sticky trap capable of collecting eggs and imprisoning mosquitoes was investigated. Methods: To evaluate the performance of the sticky BR-OVT trap, tests were carried out in the neighborhoods of Caixa d'Água and Passarinho (Olinda-PE-Brasil) between August 2011 and June 2012. Sixty traps were installed in the indoor areas of residences in the two districts. Results: During the 11-month study, 0.52 [standard deviation $(\mathrm{SD})=1.52$ ] Culex egg rafts, $2.16(\mathrm{SD}=4.78)$ C. quinquefasciatus/trap/month, and $0.55(\mathrm{SD}=1.28)$ Aedes/trap/month were caught. Female specimens predominated the traps (59\% of C. quinquefasciatus and 96\% of Aedes spp.). Conclusions: The results demonstrated that the sticky BR-OVT trap is a useful tool for the collection of adult culicids of medical importance and offers an innovative way to collect C. quinquefasciatus eggs and adults in a single trap.
\end{abstract}

Keywords: Egg collecting. Adhesive trap. Entomological surveillance. Mosquito control.

\section{INTRODUCTION}

Culex quinquefasciatus is a mosquito with vector competence for the transmission of different pathogens, such as arthropodborne viruses in the families Flaviviridade (Saint Louis encephalitis virus ${ }^{1}$ and West Nile virus ${ }^{2-4}$ ) and Bunyaviridae (Oropouche virus ${ }^{5,6}$ ), as well as worms that cause lymphatic filariasis ${ }^{7,8}$. Zika virus has also recently been found in the salivary glands of this mosquito ${ }^{9,10}$. In addition, this species causes great nocturnal discomfort because of the preference of its females to feed on blood at night ${ }^{1,11,12}$.

Especially in regions with tropical climates, where temperature and precipitation rates are high, the presence of C. quinquefasciatus is frequent and abundant ${ }^{1,11,13}$. However this mosquito is distributed throughout the world and its occurrence is associated with urban areas with precarious conditions of environment and sanitation. Dense populations of this mosquito are found in urban areas that present artificial breeding sites such

Corresponding author: $\mathrm{Dr}^{\mathrm{a}}$ Cláudia Maria Fontes de Oliveira e-mail: claudia@cpqam.fiocruz.br

Received 30 October 2017

Accepted 18 May 2018 as pits, open ditches, and sewage, with large amounts of organic matter, where mosquito females prefer to lay their $\operatorname{eggs}^{1,11,12}$.

In Brazil, the control of $C$. quinquefasciatus is determined based on local needs ${ }^{14,15}$. In the State of Pernambuco (Northeastern region of the country), the municipalities of Recife, Olinda, and Jaboatão dos Guararapes have developed control actions since 2002 as part of the Global Programme to Eliminate Lymphatic Filariasis $^{14,15}$. Moreover, the mapping and treatment of preferential breeding sites for C. quinquefasciatus is addressed in the National Plan for the Elimination of Filariasis ${ }^{16}$. However, no method is employed to evaluate control measures targeting this mosquito, unlike the National Program for Dengue Control (PNCD), which promotes control actions targeting Aedes aegypti and describes evaluation methods for such actions ${ }^{17}$.

The use of traps can contribute to both the monitoring and reduction in population densities of mosquitoes ${ }^{18-25}$. Among the traps described in the literature, some are used for the collection of $\operatorname{eggs}^{26-28}$ and others are used to catch adult culicids, such as those with light attractors ${ }^{29}$, that target gravid females and can assist in the detection of circulating pathogen $\mathrm{s}^{30-33}$, that involve the release of substances such as $\mathrm{CO}_{2}$ to attract and capture mosquitoes ${ }^{34,35}$, and that employ sticky traps, which are based on the use of physical characteristics as a strategy to attract and imprison mosquitoes ${ }^{36-43}$. 
The addition of a sticky edge to the BR-OVT oviposition trap, which was originally designed to collect eggs of the species C. quinquefasciatus ${ }^{27}$, could give this trap a huge operational advantage, as it would combine the capacity to collect C. quinquefasciatus eggs and adults in a single device. Thus, the goal of the present study was to conduct a field evaluation of the sticky BR-OVT trap as a tool for monitoring the population density of culicids. The use of a simple trap could contribute to the monitoring and evaluation of the population densities of C. quinquefasciatus and offers the advantage of being a passive collection tool, which therefore does not rely on the capture skills of the operator.

\section{METHODS}

\section{Study area}

The study was conducted in two neighborhoods in the city of Olinda, Brazil ( $\left.08^{\circ} 01^{\prime} 48^{\prime \prime} \mathrm{S} 34^{\circ} 51^{\prime} 42^{\prime \prime} \mathrm{W}\right)$, which has approximately 390,000 inhabitants distributed in an area encompassing $41 \mathrm{~km}^{2}$ (IBGE; 2010) $)^{44}$. The neighborhoods Caixa d'Água (CD) and Passarinho (PA) have 4,600 properties (residences, commercial points, and public institutions). Both are urban areas with no sewage network and have similar topographies, with flat and raised areas. During the study period (August 2011 to June 2012), the majority of streets in PA were not paved.

\section{Traps used in study}

BR-OVT oviposition trap (Figure 1): the device was composed of a black polyethylene box $(13 \times 35 \times 24 \mathrm{~cm})$ with a central opening $(16 \times 9 \mathrm{~cm})$ on the upper side and a black recipient $(21 \times 3.5 \mathrm{~cm})$ with a one-liter capacity within the box ${ }^{27}$. The traps were deployed with $800 \mathrm{~mL}$ of water and $1 \mathrm{~g}$ of biolarvicide containing Bacillus thuringiensis israelensis (Bti) (Vectobac ${ }^{\circledR}$ - Formulação CG).

Sticky BR-OVT trap: this was a version of the BR-OVT oviposition trap designed to imprison mosquitoes on the sticky edge (Figure 2). Adaptations included: 1) increased capacity of the inner recipient to $4 \mathrm{~L} ; 2$ ) addition of a sticky border on the recipient of the black polyethylene with a central opening $(13 \times 19 \mathrm{~cm})$ covered with a thin layer of Colly ${ }^{\circledR}$ entomological glue on the upper and lower surfaces. The traps were deployed with $3 \mathrm{~L}$ of water and $1 \mathrm{~g}$ of Bti Vectobac ${ }^{\circledR}$.

Ovitrap: the oviposition trap was composed of a round recipient of black plastic with a capacity of $1.2 \mathrm{~L}$. Two

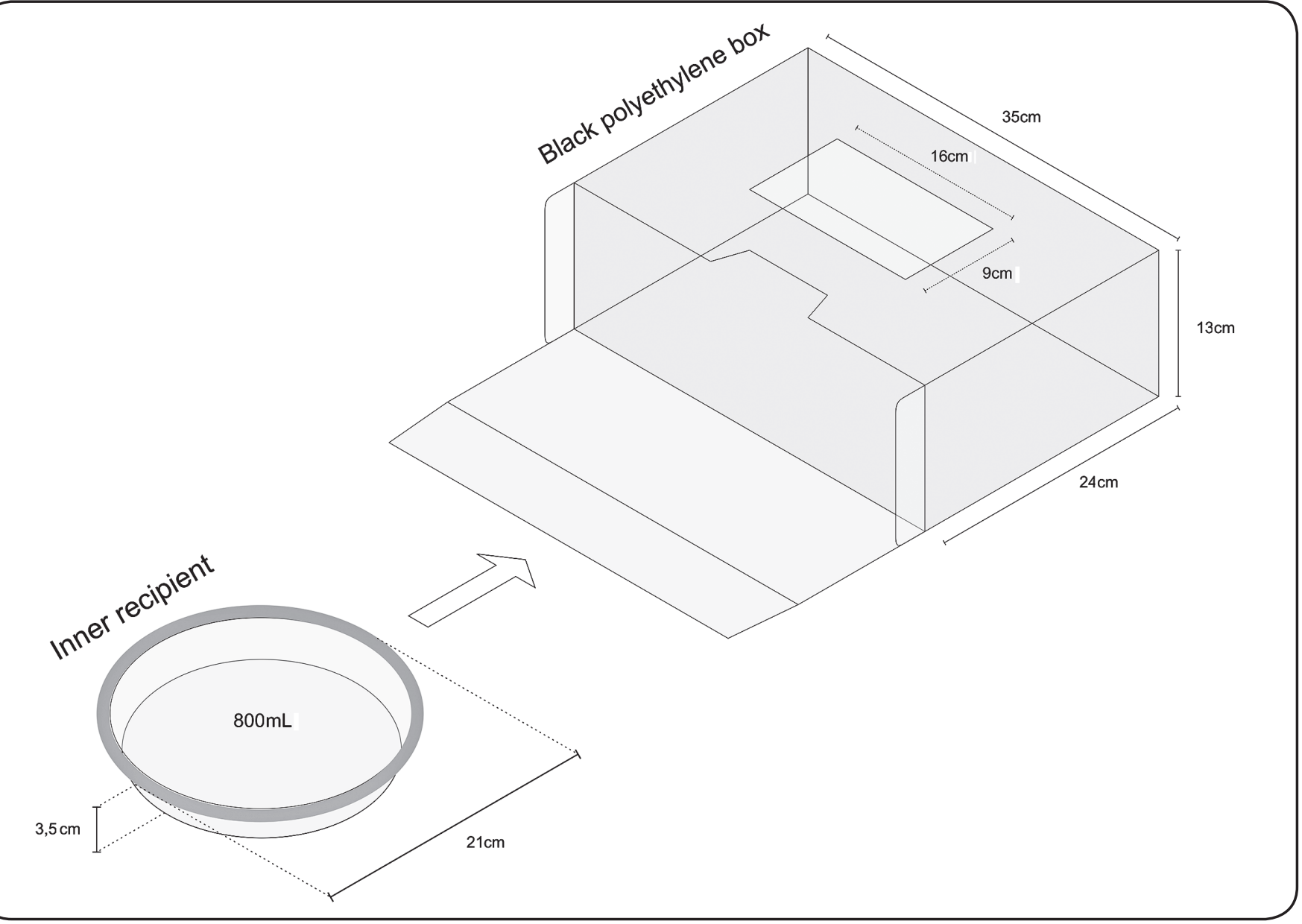

FIGURE 1: BR-OVT oviposition trap for collection of Culex quinquefasciatus eggs. BR-OVT: oviposition trap. 


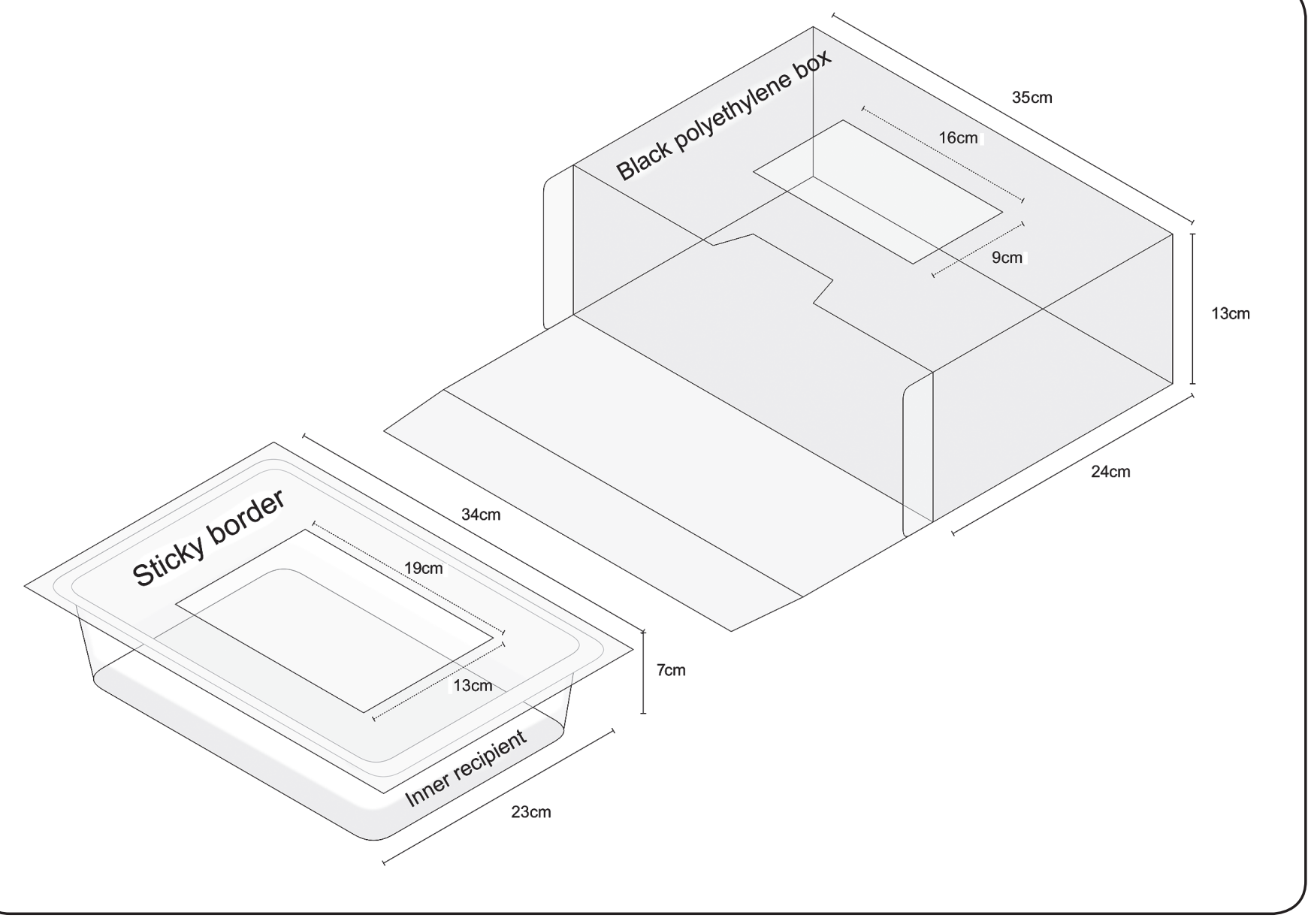

FIGURE 2: Sticky BR-OVT oviposition trap - adapted from BR-OVT trap to imprison adult mosquitoes. BR-OVT: oviposition trap; Sticky BR-OVT: a trap that is capable to collect culicids eggs and adult mosquitoes.

paddles $(5 \times 15 \mathrm{~cm})$ were placed on the inner wall for oviposition. This model is similar to the trap described by Regis et al. ${ }^{28}$. The ovitraps were installed with $1 \mathrm{~L}$ of water and $1 \mathrm{~g}$ of Bti Vectobac ${ }^{\circledR}$ to obtain information on the infestation of mosquitoes of the genus Aedes in the study area.

\section{Experimental design}

Three experimental groups were formed to determine the capacity of the sticky BR-OVT trap. In Experiment 1, one sticky BR-OVT trap was installed in indoor areas of 15 residences in both neighborhoods (CD and PA) to evaluate the potential of this trap to collect $C$. quinquefasciatus adults and eggs. In Experiment 2, two traps (one sticky BR-OVT and one conventional BR-OVT) were installed on the ground level at a distance of $1.5 \mathrm{~m}$ from one another in the indoor areas of 15 residences in the neighborhood of PA to determine the capacity of the sticky BR-OVT to collect Culex eggs in comparison with the conventional BR-OVT trap. In Experiment 3, two traps (one sticky BR-OVT and one ovitrap) were installed at 15 residences in $\mathrm{CD}$ to determine the potential of the proposed sticky trap regarding the detection of mosquitoes of the genus Aedes. Ovitraps are recognized as sensitive to the detection of this genus. The ovitraps were installed in the outdoor areas and the sticky BR-OVT traps were installed in indoor areas, maintaining the original strategy of installation for this type of trap.

The maintenance and monitoring of all traps were performed in 28-day cycles, totaling 11 evaluation cycles (August 2011 to June 2012). At the end of each cycle, the eggs and mosquitoes were counted and the sticky edges, sticks, water and biolarvicide were replaced. The specimens were identified to the genus level based on morphological characteristics ${ }^{45}$ observed under a stereomicroscope at the laboratory of the Olinda Environmental Surveillance Center [Centro de Vigilância Ambiental de Olinda (CEVAO)]. Because of the possibility of larval eclosion, C. quinquefasciatus egg rafts collected in the BR-OVT traps (sticky and conventional) were counted on a weekly basis throughout the study.

\section{Statistical analysis}

The efficacy of the sticky BR-OVT trap was evaluated based on mean and standard deviation values of the mosquitoes and egg rafts collected in each trap per month. Mean positivity was determined by the quotient between the number of positive traps (at least one mosquito/raft/egg) and the total number of 
traps deployed. An analysis of variance (ANOVA) followed by Tukey's post hoc test was used for the comparative analysis of the number of mosquitoes, egg rafts, and eggs collected during the study. The Shapiro-Wilk test and Levene's test were used to determine the normality of the data and equal variance, respectively. All analyses were performed with the Statistica 7.1 software program and a $p$-value $<0.05$ was considered indicative of statistical significance.

\section{RESULTS}

\section{Performance of sticky BR-OVT for collection of eggs and mosquitoes}

The data demonstrated that the sticky BR-OVT traps were capable of catching adults of the genera Culex and Aedes, as well as collecting $C$. quinquefasciatus egg rafts. The traps $(\mathrm{n}=60)$ evaluated in the different experiments caught a total of 1,430 specimens of C. quinquefasciatus, $59 \%$ of which were females, and 363 specimens of Aedes spp. 96\% of which were females. More than 350 egg rafts were also collected.

The sticky BR-OVT traps deployed individually (Experiment 1) caught 686 specimens of $C$. quinquefasciatus: 170 [1 (SD 2.53) Culex/trap/cycle] in PA and 517 [3.1 (SD 4.73) Culex/trap/cycle] in CD. A statistically significant difference was found between neighborhoods ( $\mathrm{F}=25,090 ; \mathrm{GL}=1,328, \mathrm{p}<0.05)$. One hundred fifteen egg rafts were also collected $[0.07$ (SD 0.5) rafts/trap/cycle in PA and 0.61 (SD 1.32) rafts/trap/cycle in CD]. In these traps, 163 specimens of Aedes were also found: 46 [0.27 (SD 0.81) Aedes/trap/cycle] in PA and 117 [0.7 (SD 1.41)Aedes/trap/cycle] in CD. No significant difference between neighborhoods was found regarding the number of mosquitoes collected.

\section{Attraction potential of sticky and conventional BR-OVT traps for collection of Culex quinquefasciatus eggs}

Three hundred twenty egg rafts were collected from the sticky and conventional BR-OVT traps installed in pairs inside homes (Experiment 2). No statistically significant difference was found in the number of egg rafts between the two types of traps (Figure 3). Eighty-eight egg rafts [0.5 (SD 1.94) rafts/trap/ cycle] were collected using the sticky BR-OVT traps, suggesting

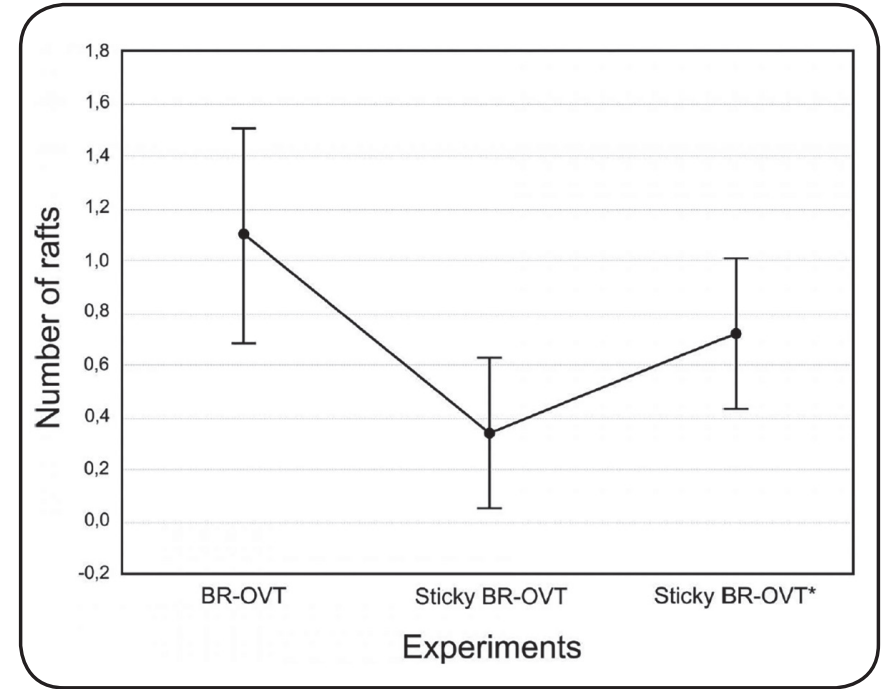

FIGURE 3: Overall variance and standard deviation (bars) of the number of egg rafts collected in BR-OVT traps, sticky BR-OVT traps deployed individually, and sticky BR-OVT traps deployed with BR-OVT traps in same residence in neighborhood of Passarinho, Olinda, Brazil; August 2011 to June 2012. BR-OVT: oviposition trap; Sticky BR-OVT: a trap that is capable to collect culicids eggs and adult mosquitoes; RAFT: the name given to the grouping of eggs of $C$. quinquefasciatus; BR-OVT sticky*: is the condition where this trap was deployed with BR-OVT in the same house.

that the presence of entomological glue did not influence the selection of the site for oviposition by Culex females. Three hundred eighty-one individuals of $C$. quinquefasciatus were also collected, $59 \%$ of which were females. Based on a visual inspection of the physiological state, 37 gravid, 21 blood-fed, and 167 unfed females were collected. Aedes spp. adults were also caught in these traps (Table 1).

\section{Sensitivity of sticky BR-OVT trap for detection of Aedes aegypti}

As mentioned above, besides collecting C. quinquefasciatus eggs and adults (Table 1), Aedes was detected in the sticky BR-OVT traps. Thus, the sensitivity of the sticky trap deployed in the interior of residences for the detection of this mosquito was evaluated (Experiment 3). The sticky traps were positive

TABLE 1: Mean, standard deviation, and positivity for egg rafts/eggs and mosquitoes (Culex and Aedes) caught in sticky BR-OVT traps, conventional BROVT traps, and ovitraps deployed in Caixa d'Água and Passarinho, City of Olinda, Brazil.

\begin{tabular}{|c|c|c|c|c|c|c|c|}
\hline \multirow{2}{*}{ Experiment } & \multirow{2}{*}{ Trap } & \multicolumn{3}{|c|}{ Mean (SD) } & \multicolumn{3}{|c|}{ Positivity (\%) } \\
\hline & & egg rafts/eggs & Culex & Aedes & egg rafts/eggs & Culex & Aedes \\
\hline \multirow[t]{2}{*}{1} & Sticky BR-OVT & $0.33(1.03)$ & $2.08(3.9)$ & $0.49(1.17)$ & 14 & 46 & 23 \\
\hline & Sticky BR-OVT & $0.5(1.94)$ & $2.3(6.57)$ & $0.59(1.13)$ & 12 & 48 & 28 \\
\hline 2 & Sticky BR-OVT & $0.92(1.8)$ & $2.2(4.19)$ & $0.61(1.6)$ & 39 & 51 & 25 \\
\hline 3 & Ovitrap & $235(220)$ & NA & NA & 98.7 & NA & NA \\
\hline
\end{tabular}

BR-OVT: oviposition trap; SD: standard deviation; NA: not applicable. 
for Aedes spp. in $29.5 \%$ of the homes. One hundred two individuals [0.61 (SD 1.60) Aedes/trap/cycle] were collected. The ovitrap confirmed the presence of the mosquito at $98.7 \%$ of the residences [235 (SD 220) eggs/ovitrap/cycle].

\section{Detection of presence of Culicids with different sticky BR-OVT trap deployment strategies}

Approximately $60 \%$ of the sticky BR-OVT traps were positive for culicids, independent of the species or lifecycle phase, and $55 \%$ of these traps were capable of detecting the presence of at least one C. quinquefasciatus egg raft and/or adult, whereas this rate was $25 \%$ for Aedes. Moreover, the concomitant occurrence of Culex and Aedes was detected in $20 \%$ of the sticky BR-OVT traps.

When deployed alone, $46 \%$ of the sticky BR-OVT traps were positive for C. quinquefasciatus, with a $14 \%$ rate for egg rafts and 23\% rate for Aedes (Table 1). Similar rates were found when the sticky BR-OVT trap was deployed with other traps, with rates of $49 \%, 26 \%$, and $26 \%$ for C. quinquefasciatus adults, egg rafts, and Aedes adults, respectively (Table 1).

\section{DISCUSSION}

The potential to attract and catch different species of culicids that transmit arthropod-borne viruses and nematodes in different phases of their lifecycle (eggs and adults) could play an important role in the control of vectors, especially in Neotropical regions, such as the Metropolitan Region of Recife. The sticky BR-OVT trap demonstrated this potential by efficiently collecting Culex quinquefasciatus adults and eggs, as well as removing Aedes spp. from the environment.

The sticky BR-OVT trap was capable of imprisoning adult specimens of Culex, removing from the environment a mean of 2.16 (SD 4.78) Culex/trap/28-day cycle. This number is higher than that described by Thornton et al. ${ }^{43}$, who deployed a sticky ovitrap [0.1 (SD 0.4) Culex females/trap/15 nights] and MosquiTRAP [0.2 (SD 0.5) Culex females/trap/15 nights] in Muheza, Tanzania. Caputo et al. ${ }^{42}$ evaluated the performance of a sticky trap with and without larvicide in two areas of Rome, Italy, and collected 1.6 (SD 0.1) and 2.3 (SD 1.1) Culex pipiens females/sticky trap, respectively. These data demonstrate that sticky traps primarily target Culex females ${ }^{37,43}$. However, the sticky BR-OVT traps collected males and females at a proportion of approximately 1:1. Similar findings are described in studies by Santos et al. ${ }^{41}$ and Facchinelli et al.$^{46}$, who evaluated the Aedes Trap and a sticky trap, respectively. Although catching females is of considerable importance to public health, the capacity to attract and collect females and males equally is useful to the estimation of population densities ${ }^{40}$.

Besides catching adult mosquitoes, the sticky BR-OVT trap demonstrated the potential to collect $C$. quinquefasciatus egg rafts. However, the number of egg rafts collected was lower than that found with the conventional BR-OVT trap, although the difference did not achieve statistical significance. This difference may be related to the capacity of the sticky trap to capture gravid females. Therefore, its use is recommended not only for monitoring, but also as a part of control strategies targeting this culicid.
The positivity rates of the sticky BR-OVT trap further demonstrate its effectiveness. Positivity for Culex ranged from 46 to $51 \%$, which is similar to the rate described by Braks and $\mathrm{Cardé}^{37}$, who evaluated the sticky grid gravid trap (sticky version of the Box gravid trap) and found that $60 \%$ of traps were positive for $C$. quinquefasciatus. In the present study, positivity with the conventional BR-OVT trap was $20 \%$, which is similar to that achieved with the sticky BR-OVT trap (12 to 39\%). In comparison to findings described by Correia et al. ${ }^{47}$ and Barbosa et al. ${ }^{48}$, who reported rates higher than $90 \%$ with conventional BR-OVT traps, the traps detected less colonization pressure in the neighborhood of PA. This demonstrates that even within a single city, neighborhoods have microenvironments that can exert an influence on the population size of culicids.

Although the sticky BR-OVT trap was developed for C. quinquefasciatus, it also demonstrated the capacity to catch Aedes in the interior of homes at a similar rate to traps designed to catch species of this genus. The performance [0.55 (SD 1.28) Aedes/trap/cycle] was similar to rates described for the AedesTrap evaluated in Recife ${ }^{41}$, Brazil [0.54 (SD 0.07) females/ trap/28 days] and the MosquiTRAP tested in the City of Belo Horizonte ${ }^{39}$, Brazil (0.11 Aedes/trap/week). Studies conducted in Rome using a sticky trap to catch Aedes albopictus reported means of 0.71 and 1.4 females/trap/day ${ }^{38}$. Using the Aedes Trap inside residences, Santos et al. ${ }^{41}$ reported positivity rates of 13 to $22 \%$ for Aedes. In the present study, this rate was between 23 and $28 \%$. Using the MosquiTRAP in the peri-domicile area of residences in the City of Belo Horizonte, Brazil, Gama et al. ${ }^{39}$ reported $26.3 \%$ positivity. Moreover, we found some imprisoned females performing death-stress oviposition, which has been described by other authors ${ }^{40,41}$.

The concomitant presence of Aedes aegypti and C. quinquefasciatus in urban environments requires permanent control measures because of the circulation of arthropod-borne viruses and other etiological agents ${ }^{1-10,49}$. Integrated control actions involving the elimination of breeding sites, the use of larvicides, traps for the collection of eggs and adults, and the popular mobilization are of great importance to the success of entomological control and surveillance programs ${ }^{50,51}$.

The sticky BR-OVT trap has the capacity to catch culicids of medical importance, especially when combined with the deployment of other traps in the same home. Moreover, the sticky BR-OVT trap has the advantage of uniting the capacity to collect C. quinquefasciatus adults and eggs, as well as Aedes spp. adults in a single device. Thus, the sticky BR-OVT trap has potential for use in surveillance programs targeting C. quinquefasciatus and A. aegypti concomitantly with another mosquito control strategies.

\section{Acknowledgments}

The authors are grateful to Daniela Bandeira and Diana Santana of the Olinda Municipal Secretary of Health for permission to conduct this study in the neighborhoods of Caixa d'Água and Passarinho in Olinda, Brazil and the field team for help conducting activities.

\section{Conflict of interests}

The authors declare that there is no conflict of interest 


\section{Financial support}

This study was supported by the Fundação de Amparo à Pesquisa do Estado de Pernambuco (FACEPE), Brazil (Grant number 13/2012- PPSUS-REDE) [Programa de Pesquisa para o Sistema Único de Saúde (PPSUS-REDE)] (Research Support. APQ-2141-4.00 / 12).

\section{REFERENCES}

1. Forattini OP. Culicidologia Médica: Identificação, Biologia, Epidemiologia. Vol. 2. São Paulo: EDUSP; 2002. 864p.

2. Sardelis MR, Turell MJ, Dohm DJ, O'Guinn ML. Vector competence of selected North American Culex and Coquillettidia mosquitoes for West Nile virus. Emerg Infect Dis. 2001;7(6):1018-22.

3. Goddard LB, Roth AE, Reisen WK, Scott TW. Vertical transmission of West Nile virus by three California Culex mosquitoes. J Med Entomol. 2003;40(6):743-6.

4. Pauvolid-Corrêa A, Morales MA, Levis S, Figueiredo LTM, CoutoLima D, Campos Z, et al. Neutralising antibodies for West Nile virus in horses from Brazilian Pantanal. Mem Inst Oswaldo Cruz. 2011;106(4):467-74.

5. Pinheiro FP, Travassos-da-Rosa AP, Travassos-da-Rosa JF, Ishak R, Freitas RB, Gomes ML, et al. Oropouche virus I. A review of clinical, epidemiological, and ecological findings. Am J Trop Med Hyg. 1981;30(1):149-60.

6. Cardoso BF, Serra OP, Heinen LBS, Zuchi N, Souza VC, Naveca $\mathrm{FG}$, et al. Detection of Oropouche virus segment $\mathrm{S}$ in patients and in Culex quinquefasciatus in the state of Mato Grosso, Brazil. Mem Inst Oswaldo Cruz. 2015;110(6):745-54.

7. Natan MB. Bancroftian filariasis in coastal north Trinidad, West Indies: intensity of transmission by Culex quinquefasciatus. Trans R Soc Trop Med Hyg. 1981;75(5):721-30.

8. White GB. Lymphatic filariasis. In: World Health Organization, editor. Geografical Distribution of Arthropod-borne Diseases and their Principal VectorsWHO/VBC/89.967. Genebra: WHO; 1989. p. 23-34.

9. Guo XX, Li CX, Deng YQ, Xing D, Liu QM, Wu Q, et al. Culex pipiens quinquefasciatus: a potential vector to transmit Zika virus. Emerg Microbes Infect. 2016;5(9):e102.

10. Guedes DRD, Paiva MHS, Donato MMA, Barbosa PP, Krokovsky L, et al. Zika virus replication in the mosquito Culex quinquefasciatus in Brazil. Emerg Microbes Infect. 2017;6(8):e69.

11. Natal D, Araújo FAA, Viana RST, Pereira LE, Ueno HM. O mosquito das águas poluídas. Saneas; 2004. p. 26-31.

12. Ministério da Saúde (MS). Guia de Vigilância do Culex quinquefasciatus. Brasília: MS; 2011. 76p.

13. Fonseca DM, Smith JL, Wilkerson RC, Fleischer RC. Pathways of expansion and multiple introductions illustrated by large genetic differentiation among worldwide populations of the southern house mosquito. Am J Trop Med Hyg. 2006;74(2):284-9.

14. Maciel A, Furtado AF, Marzochi KBF. Views on the municipalization of lymphatic filariasis control in greater metropolitan Recife. Cad Saúde Pública. 1999;15(1):195-203.

15. Rocha A, Marcondes M, Nunes JRV, Miranda T, Veiga J, Araújo $\mathrm{P}$, et al. Programa de controle e eliminação da filariose linfática: uma parceria da Secretaria de Saúde de Olinda-PE, Brasil, com o Serviço de Referência Nacional em Filarioses. Rev Patol Trop. 2010;39(3):233-49.

16. Ministério da Saúde (MS). Guia de vigilância epidemiológica e eliminação da filariose linfática. Brasília: MS; 2009. 80p.
17. Ministério da Saúde (MS). Programa Nacional de Controle da Dengue (PNCD). Fundação Nacional de Saúde. Brasília: MS; 2002. 28p.

18. Barbosa RMR, Regis LN. Monitoring temporal fluctuations of Culex quinquefasciatus using oviposition traps containing attractant and larvicide in an urban environment in Recife, Brazil. Mem Inst Oswaldo Cruz. 2011;106(4):451-5.

19. Steffler LM, Marteis LS, Dolabella SS, Cavalcanti SCH, Santos RLC. Risk of dengue occurrence based on the capture of gravid Aedes aegypti females using MosquiTRAP. Mem Inst Oswaldo Cruz. 2011;106(3):365-7.

20. Regis L, Acioli RV, Silveira-Junior JC, de Melo-Santos MAV, da Cunha MCS, Souza F, et al. Characterization of the spatial and temporal dynamics of the dengue vector population established in urban areas of Fernando de Noronha, a Brazilian oceanic island. Acta Trop. 2014;137:80-7.

21. Snetselaar J, Andriessen R, Suer RA, Osinga AJ, Knols BGJ, Farenhorst M. Development and evaluation of a novel contamination device that targets multiple life-stages of Aedes aegypti. Parasit Vectors. 2014;7:200.

22. Codeço CT, Lima AWS, Araújo SC, Lima JBP, Maciel-de-Freitas R, Honório NA, et al. Surveillance of Aedes aegypti: comparison of house index with four alternative traps. PLoS Negl Trop Dis. 2015;9(2):e0003475.

23. Hesson JC, Ignell R, Hill SR, Östman Ö, Lundström JO. Trapping biases of Culex torrentium and Culex pipiens revealed by comparison of captures in CDC traps, ovitraps and gravid traps. J Vector Ecol. 2015;40(1):158-63.

24. Okorie PN, Davies E, Ogunmola OO, Ojurongbe O, Saka Y, Okoeguale B, et al. Lymphatic filariasis baseline survey in two sentinel sites of Ogun state, Nigeria. Pan Afr Med J. 2015;20:397.

25. Santos CF, Silva AC, Rodrigues RA, Jesus JSR, Borges MAZ. Inventory of mosquitoes (Diptera: Culicidae) in conservation units in Brazilian Tropical dry forests. Rev Inst Med Trop S Paulo. 2015;57(3):227-32.

26. Fay RW, Eliason DA. A prefered oviposition site as a surveillance method for Aedes aegypti. Mosq News. 1966;26:531-5.

27. Barbosa RMR, Souto A, Eiras AE, Regis L. Laboratory and field evaluation of an oviposition trap for Culex quinquefasciatus (Diptera: Culicidae). Mem Inst Oswaldo Cruz. 2007;102(5):523-9.

28. Regis L, Monteiro AM, Melo-Santos MAV, Silveira-Júnior JC, Furtado AF, Acioli RV, et al. Developing new approaches for detecting and preventing Aedes aegypti population outbreaks: basis for surveillance, alert and control system. Mem Inst Oswaldo Cruz. 2008; 103(1):50-9.

29. Silva JS, Couri MS, Giupponi APL, Alencar J. Mosquito fauna of the Guapiaçu Ecological Reserve, Cachoeiras de Macacu, Rio de Janeiro, Brazil, collected under the influence of different color CDC light traps. J Vector Ecol. 2014;39(2):384-94.

30. Reiter P. A portable battery-powered trap for collecting gravid Culex mosquitoes. Mosq News. 1983;43:496-8.

31. Cummings R. Design and use of a modified Reiter gravid mosquito trap for mosquito-borne encephalitis surveillance in Los Angeles County, California. Proc Mosq Vector Control Assoc Calif. 1992;60:170-6.

32. Allan SA, Kline D. Evaluation of various attributes of gravid female traps for collection of Culex in Florida. J Vector Ecol. 2004;29(2):285-94.

33. Donatti JE, Gomes AC. Adultrap: Descrição de armadilha para adulto de Aedes aegypti (Diptera, Culicidae). Rev Bras Entomol. 2007;51(2):255-6. 
34. Krockel U, Rose A, Eiras AE, Geier M. New tools for surveillance of adult yellow fever mosquitoes: comparison of trap catches with human landing rates in an urban environment. J Am Mosq Control Assoc. 2006;22(2):229-38.

35. Jawara M, Awolola TS, Pinder M, Jeffries D, Smallegange RC, Takken W, et al. Field-testing of different chemical combinations as odour baits for trapping wild mosquitoes in The Gambia. PLoS ONE. 2011;6(5):e19676.

36. Ordóñez-Gonzalez JG, Mercado-Hernandez R, Flores-Suarez AE, Fernández-Salas I. The use of sticky ovitraps to estimate dispersal of Aedes aegypti in Northeastern Mexico. J Am Mosq Control Assoc. 2001;17(2):93-7.

37. Braks MAH, Cardé RT. Improving efficacy of box gravid traps for collecting Culex quinquefasciatus. J Vector Ecol. 2007;32(1):83-9.

38. Facchinelli L, Valerio L, Pombi M, Reiter P, Costantini C, DellaTorre A. Development of a novel sticky trap for container breeding mosquitoes and evaluation of its sampling properties to monitor urban populations of Aedes albopictus. Med Vet Entomol. 2007;21:183-95.

39. Gama RA, Silva EM, Silva IM, Resende MC, Eiras AE. Evaluation of the sticky MosquiTRAPTM for detecting Aedes (Stegomyia) aegypti (L.) (Diptera: Culicidae) during the dry season in Belo Horizonte, Minas Gerais, Brazil. Neotrop Entomol. 2007;36(2): 294-302.

40. Chadee DD, Ritchie SA. Efficacy of sticky and standard ovitraps for Aedes aegypti in Trinidad, West Indies. J Vector Ecol. 2010;35(2):395-400.

41. Santos EMM, Melo-Santos MAV, Oliveira CMF, Correia JC, Albuquerque CMR. Evaluation of a sticky trap (AedesTraP), made from disposable plastic bottles, as a monitoring tool for Aedes aegypti populations. Parasit Vectors. 2012;5:195.

42. Caputo B, Ienco A, Manica M, Petrarca V, Rosa R, Della-Torre A. New sticky traps to monitor urban mosquitoes with a case study to assess the efficacy of insecticide control strategies in temperate areas. Parasit Vectors. 2015;8:134.
43. Thornton JH, Batengana BM, Eiras AE, Irish SR. Evaluation of collection methods for Culex quinquefasciatus, Aedes aegypti, and Aedes simpsoni in northeastern Tanzania. J Vector Ecol. 2016;41(2):265-70.

44. Instituto Brasileiro de Geografia e Estatística (IBGE). Cidades. Olinda: IBGE; 2010. Disponível em: https://cidades.ibge.gov.br/ brasil/pe/olinda/panorama.

45. Consoli RAGB, Lourenço-de Oliveira R. Principais Mosquitos de Importância Sanitária no Brasil. Rio de Janeiro: Editora Fiocruz; 1994. 225p.

46. Facchinelli L, Koenraadt CJM, Fanello C, Kijchalao U, Valerio L, Jones JW, et al. Evaluation of a sticky trap for collecting Aedes (Stegomyia) adults in a dengue-endemic area in Thailand. Am J Trop Med Hyg. 2008;78(6):904-9.

47. Correia JC, Barbosa RMR, Oliveira CMF, Albuquerque CMR. Residential characteristics aggravating infestation by Culex quinquefasciatus in a region of Northeastern Brazil. Rev Saúde Pública. 2012;46(6):935-41.

48. Barbosa RMR, Regis L, Vasconcelos R, Leal WS. Culex mosquitoes (Diptera: Culicidae) egg laying in traps loaded with Bacillus thuringiensis variety israelensis and baited with Skatole. Behavior Chem Ecology. 2010;47(3):345-8.

49. Albuquerque IGC, Marandino R, Mendonça AP, Nogueira RMR, Vasconcelos PFC, Guerra LRG, et al. Chikungunya virus infection: report of the first case diagnosed in Rio de Janeiro, Brazil. Rev Soc Bras Med Trop. 2012;45(1):128-9.

50. Regis LN, Acioli RV, Silveira-Júnior JC, Melo-Santos MAV, Souza WV, Ribeiro CMN, et al. Sustained Reduction of the Dengue Vector Population Resulting from an Integrated Control Strategy Applied in Two Brazilian Cities. PLoS ONE. 2013;8(7):e67682.

51. Barrera R, Amador M, Acevedo V, Hemme RR, Félix G. Sustained, area-wide control of Aedes aegypti using CDC autocidal gravid ovitraps. Am J Trop Med Hyg. 2014;91(6):1269-76. 